Jurnal Riset Sistem Informasi Dan Teknik Informatika (JURASIK)

Volume 5 Nomor 2 Agustus, pp 187-193

ISSN: 2527-5771/EISSN: 2549-7839

https://tunasbangsa.ac.id/ejurnal/index.php/jurasik

\title{
Otomasi Perencanaan Produksi pada Pondok Pesantren
}

\author{
S A Rahmasari' ${ }^{1}$ A Juliasari ${ }^{2}$, W K Febryanto ${ }^{3}$ and M A Yaqin ${ }^{4}$ \\ 1,2,3,4 Jurusan Teknik Informatika, Fakultas Sains dan Teknologi \\ Universitas Islam Negeri Maulana Malik Ibrahim Malang \\ 116650076@student.uin-malang.ac.id, 216650085@student.uin-malang.ac.id, \\ 316650109@student.uin-malang.ac.id, 4yaqinov@ti.uin-malang.ac.id
}

\begin{abstract}
Production planning is very necessary in a business process that aims to minimize the total cost of production. In this research, automation of production planning using data based on the Islamic boarding school business processes. This research uses descriptive research which aims to obtain information in the implementation of the business process planning of Islamic boarding school. The calculation of production costs in this study was carried out in Microsoft Excel by determining the total targets and raw materials of the Islamic boarding school business process, then calculating the production costs of the Islamic boarding school process until finding the optimal production costs for each student for 3 years. - The year of study is Rp. 1,242,542 rupiah / Islamic student for a total of 300 Islamic students.
\end{abstract}

Keyword: Automation, Production planning, Islamic Boarding School

\begin{abstract}
Abstrak
Perencanaan produksi sangat diperlukan dalam sebuah proses bisnis yang bertujuan untuk meminimalkan total biaya produksi. Dalam penelitian ini dilakukan otomatisasi perencanaan produksi menggunakan data yang didasarkan pada proses bisnis pondok pesantren. Penelitian ini menggunakan penelitian deskriptif dimana bertujuan untuk memperoleh informasi dalam pelaksaan perencanaan proses bisnis pondok pesantren. Perhitungan biaya produksi pada penelitian ini dilakukan di dalam Microsoft Excel dengan menentukan total target dan bahan baku dari proses bisnis pondok pesantren, selanjutnya menghitung biaya produksi dari proses pondok pesantren ini hingga ditemukan biaya produksi optimal untuk setiap santri selama 3 tahun. -Tahun belajar adalah Rp. 1.242.542 rupiah /santri untuk total santri sebanyak 300.
\end{abstract}

Kata kunci: Otomasi, Perencanaan Produksi, Pondok Pesantren

\section{PENDAHULUAN}

Pondok Pesantren merupakan sebuah organisasi (enterprise) di bidang pendidikan sehingga dibutuhkan sebuah perencanaan produksi. Perencanaan produksi dapat dilakukan kegiatan sebelum dilaksanakan kegiatan produksi dengan mempertimbangkan jumlah permintaan berdasarkan sumber daya dan kapasitas yang dimiliki oleh suatu instansi. Penentuan produk dalam jumlah optimal yang akan diproduksi menjadi kunci dalam perencanaan produksi. Menurut [1] dalam jurnal yang ditulis oleh Nurfatimah Rahmadani dan Andi Wawo Activity Based Costing system merupakan metode perbaikan dari sistem tradisional. Activity Based Costing system ini merupakan metode perhitungan biaya yang dapat memberikan alokasi biaya overhead pabrik yang lebih akurat dan relevan. Activity Based Costing (ABC) 
Jurnal Riset Sistem Informasi Dan Teknik Informatika (JURASIK)

Volume 5 Nomor 2 Agustus, pp 187-193

ISSN: 2527-5771/EISSN: 2549-7839

https://tunasbangsa.ac.id/ejurnal/index.php/jurasik

memiliki penerapan penelusuran biaya yang lebih menyeluruh dibandingkan dengan akuntansi biaya tradisional. Namun, beberapa pondok pesantren ada yang belum bisa membuat RAB (Rancangan Anggaran Belanja). Selain itu masih ada juga pondok pesantren yang masih minim transparasi anggaran dan akuntabilitasnya sehingga hal ini dapat menyebabkan proses tidak efektif dan gagalnya proses produksi. Perencanaan produksi sangat dibutuhkan dalam mengatasi hal ini.

\section{METODOLOGI PENELITIAN}

Otomasi adalah suatu teknologi yang membuat sebuah proses dapat dikerjakan tanpa bantuan manusia, otomasi (Automatic) di implementasikan dengan menggunakan program perintah yang dikendalikan oleh sistem control yang kemudian akan dieksekusi oleh sistem kontrol [2]. Perencanaan produksi merupakan perencanaan tentang produk apa dan berapa yang akan diproduksi oleh perusahaan yang bersangkutan dalam satu periode yang akan datang. Perencanaan produksi merupakan bagian dari perencanaan operasional di dalam perusahaan. Dalam penyusunan perencanaan produksi, hal yang perlu dipertimbangkan adalah adanya optimasi produksi sehingga akan dapat dicapai tingkat biaya yang paling rendah untuk pelaksanaan proses produksi tersebut [3]. Perencanaan produksi juga didefinisikan sebagai proses untuk memproduksi barang-barang pada suatu periode tertentu sesuai dengan yang diramalkan atau dijadwalkan melalui pengorganisasian sumber daya seperti tenaga kerja, bahan baku, mesin dan peralatan lainnya. Perencanaan produksi menuntut penaksiran atas permintaan produk atau jasa yang diharapkan akan disediakan perusahaan di masa yang akan datang. Dengan demikian, peramalan merupakan baguan integral dari perencanaan produksi [4][5]. Penelitian menggunakan metode deskriptif yakni jenis penelitian yang hanya menggambarkan, Meringkas berbagai situasi guna mendapatkan data yang diingginkan, dalam hal ini adalah proses bisnis Produksi pada pondok pesantren. Dalam memperoleh data yang dibutuhkan sebagai bahan penelitian menggunakan beberapa teknik atau metode untuk mendapatkannya, yakni dengan melakukan wawancara dan observasi guna mendapatkan data yang harapkan sesuai kebutuhan penelitian.

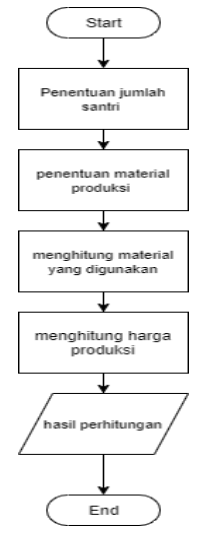

Gambar 1. Tahapan Penelitian

Otomasi Perencanaan Produksi pada Pondok Pesantren (S A Rahmasari) |188 
Adapun 5 tahapan yang dilakukan pada penelitian ini, yakni:

a) Penentuan kapasitas produksi pondok pesantren dengan target lulusan sebesar 100 santri.

b) Menentukan jumlah material yang akan digunakan dalam proses produksi

c) Menghitung harga material yang di gunakan dalam proses produksi

d) Menghitung biaya produksi, tujuannya agar mengetahui berapa beban biaya setiap santri.

\section{HASIL DAN PEMBAHASAN}

Agar dapat memproduksi lulusan sejumlah 100 santri, dibutuhkan sub sistem untuk menginput dan sarana produksi. Dalam perencanaan produksi pada pondok pesantren, input dan sarana yang harsu diperhatikan adalah sarana prasarana, bangunan, buku, pengajar, dan kegiatan pendukung pondok pesantren lainnya. Berikut adalah gambaran yang dibutuhkan oleh setiap santri sebagai berikut:

Tabel 1. Data Produksi

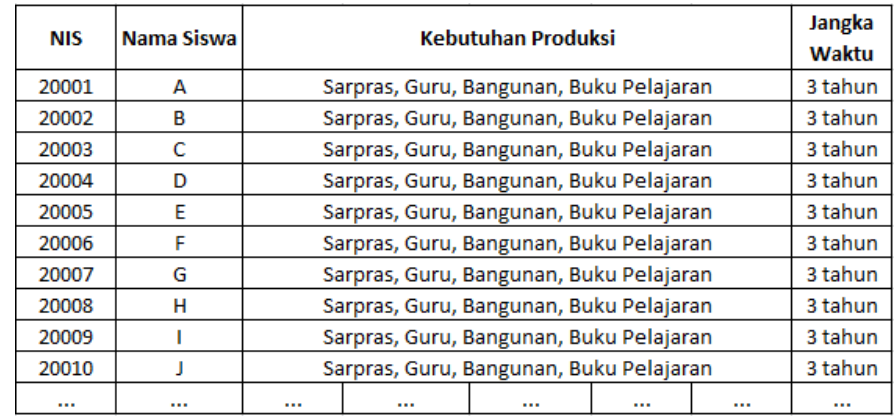

Tabel 2. Data Biaya Sarana Prasarana

\begin{tabular}{|c|c|lr|lr|}
\hline No & Jenis & \multicolumn{2}{|c|}{ Biaya Satuan } & \multicolumn{2}{|c|}{ Biaya Total } \\
\hline 1 & meja kursi guru & $\mathrm{Rp}$ & 350.000 & $\mathrm{Rp}$ & 5.250 .000 \\
\hline 2 & papan tulis & $\mathrm{Rp}$ & 200.000 & $\mathrm{Rp}$ & 1.875 .000 \\
\hline 3 & meja kursi santri & $\mathrm{Rp}$ & 350.000 & $\mathrm{Rp}$ & 21.000 .000 \\
\hline 4 & sound system & $\mathrm{Rp}$ & 300.000 & $\mathrm{Rp}$ & 2.812 .500 \\
\hline 5 & mimbar & $\mathrm{Rp}$ & 3.000 .000 & $\mathrm{Rp}$ & 3.000 .000 \\
\hline 6 & sanyo & $\mathrm{Rp}$ & 500.000 & $\mathrm{Rp}$ & 3.000 .000 \\
\hline 7 & lampu & $\mathrm{Rp}$ & 35.000 & $\mathrm{Rp}$ & 32.812 .500 \\
\hline 8 & papan pengumuman & $\mathrm{Rp}$ & 80.000 & $\mathrm{Rp}$ & 320.000 \\
\hline 9 & papan struktur org & $\mathrm{Rp}$ & 80.000 & $\mathrm{Rp}$ & 320.000 \\
\hline 10 & stempel pondok & $\mathrm{Rp}$ & 30.000 & $\mathrm{Rp}$ & 60.000 \\
\hline 11 & stempel madrasah & $\mathrm{Rp}$ & 30.000 & $\mathrm{Rp}$ & 60.000 \\
\hline 12 & Buku pendaftaran & $\mathrm{Rp}$ & 100.000 & $\mathrm{Rp}$ & 400.000 \\
\hline 13 & Buku Absensi & $\mathrm{Rp}$ & 20.000 & $\mathrm{Rp}$ & 280.000 \\
\hline 14 & 3uku kegiatan menga & $\mathrm{Rp}$ & 30.000 & $\mathrm{Rp}$ & 300.000 \\
\hline 15 & Buku kendali & $\mathrm{Rp}$ & 20.000 & $\mathrm{Rp}$ & 6.000 .000 \\
\hline 16 & Buku keamanan & $\mathrm{Rp}$ & 20.000 & $\mathrm{Rp}$ & 6.000 .000 \\
\hline 17 & almari santri & $\mathrm{Rp}$ & 300.000 & $\mathrm{Rp}$ & 90.000 .000 \\
\hline 18 & almari quran & $\mathrm{Rp}$ & 500.000 & $\mathrm{Rp}$ & 2.000 .000 \\
\hline 19 & Tempat Sampah & $\mathrm{Rp}$ & 30.000 & $\mathrm{Rp}$ & 2.220 .000 \\
\hline 20 & jam dinding & $\mathrm{Rp}$ & 65.000 & $\mathrm{Rp}$ & 1.040 .000 \\
\hline 21 & listrik & $\mathrm{Rp}$ & 1.000 .000 & $\mathrm{Rp}$ & 2.000 .000 \\
\hline & Total & & & $\mathrm{Rp}$ & 180.750 .000 \\
\hline & & & &
\end{tabular}


Jurnal Riset Sistem Informasi Dan Teknik Informatika (JURASIK)

Volume 5 Nomor 2 Agustus, pp 187-193

ISSN: 2527-5771/EISSN: 2549-7839

https://tunasbangsa.ac.id/ejurnal/index.php/jurasik

Diketahui harga meja kursi dipasaran Rp. 350.000 dengan batas pemakaian maksimum selama 5 tahun. Maka biaya yang dibutuhkan dalam pengadaan kursi adalah:

Harga meja kursi satuan $\times$ Jumlah Santri

Batas maksimum pemakaian
Total $=\frac{350.000 \times 300}{5}$
Total $=21.000 .000$

Biaya pengadaan sarana prasarana yang lainnya dapat juga menggunakan metode perhitungan yang sama seperti sebelumnya. Kemudian jumlah semua biaya pengadaan per unit sehingga didapatkan hasil seperti pada Tabel 4.2 sebagai berikut :

Total Biaya $=\sum \frac{\text { Harga satuan } \times \text { Jumlah santri }}{\text { Batas maksimum pemakai }}$

Tabel 3. Biaya Pengajar dan SDM

\begin{tabular}{|c|c|c|c|c|c|c|c|c|c|c|}
\hline No & Jabatan & Bidang & Mapel & Tunjangan & Tarif per Jam & & Gaji & Jumlah Tenaga & & Total \\
\hline 1 & Ketua & - & - & Rp1.000.000 & Rp 100.000 & $\mathrm{Rp}$ & 3.000 .000 & 1 & $\mathrm{Rp}$ & 3.000 .000 \\
\hline 2 & wakil ketua & - & - & - & Rp 50.000 & $\mathrm{Rp}$ & 1.000 .000 & 1 & $\mathrm{Rp}$ & 1.000 .000 \\
\hline 3 & sekretaris $1 \& 2$ & - & - & - & Rp 50.000 & $\mathrm{Rp}$ & 1.000 .000 & 2 & $\mathrm{Rp}$ & 2.000 .000 \\
\hline 4 & Bendehara 1 \& 2 & - & - & - & Rp 50.000 & $\mathrm{Rp}$ & 1.000 .000 & 2 & $\mathrm{Rp}$ & 2.000 .000 \\
\hline 5 & Bid. Keamanan & - & - & - & Rp 50.000 & $\mathrm{Rp}$ & 1.000 .000 & 2 & $\mathrm{Rp}$ & 2.000 .000 \\
\hline 6 & Bid. Kebersihan & - & - & - & Rp 50.000 & $\mathrm{Rp}$ & 1.000 .000 & 4 & $\mathrm{Rp}$ & 4.000 .000 \\
\hline 7 & Bid. Kesantrian & - & - & - & Rp 50.000 & $\mathrm{Rp}$ & 1.000 .000 & 4 & $\mathrm{Rp}$ & 4.000 .000 \\
\hline 8 & Bid. Pengairan & - & - & - & Rp 50.000 & $\mathrm{Rp}$ & 1.000 .000 & 2 & $\mathrm{Rp}$ & 2.000 .000 \\
\hline 9 & Bid. Perlengkapan & - & - & - & Rp 50.000 & $\mathrm{Rp}$ & 1.000 .000 & 4 & $\mathrm{Rp}$ & 4.000 .000 \\
\hline 10 & Bid. Humas & - & - & - & Rp 50.000 & $\mathrm{Rp}$ & 1.000 .000 & 2 & $\mathrm{Rp}$ & 2.000 .000 \\
\hline 11 & Pendidik & Guru & Pendidikan Agama & - & Rp 50.000 & $\mathrm{Rp}$ & 1.250 .000 & 1 & $\mathrm{Rp}$ & 1.562 .500 \\
\hline 12 & Pendidik & Guru & Pendidikan Kwn & - & Rp 50.000 & $\mathrm{Rp}$ & 1.250 .000 & 1 & $\mathrm{Rp}$ & 1.562 .500 \\
\hline 13 & Pendidik & Guru & Bahasa Indonesia & - & Rp 50.000 & $\mathrm{Rp}$ & 1.875 .000 & 2 & $\mathrm{Rp}$ & 3.515 .625 \\
\hline 14 & Pendidik & Guru & Bahasa Inggris & - & Rp 50.000 & $\mathrm{Rp}$ & 1.875 .000 & 2 & $\mathrm{Rp}$ & 3.515 .625 \\
\hline 15 & Pendidik & Guru & Matematika & - & Rp 50.000 & $\mathrm{Rp}$ & 1.875 .000 & 2 & $\mathrm{Rp}$ & 3.515 .625 \\
\hline 16 & Pendidik & Guru & Ilmu Pengetahuan Alam & - & Rp 50.000 & $\mathrm{Rp}$ & 1.875 .000 & 2 & $\mathrm{Rp}$ & 3.515 .625 \\
\hline 17 & Pendidik & Guru & IImu Pengetahuan Sosial & - & Rp 50.000 & $\mathrm{Rp}$ & 1.250 .000 & 1 & $\mathrm{Rp}$ & 1.562 .500 \\
\hline 18 & Pendidik & Guru & Seni Budaya & - & Rp 50.000 & $\mathrm{Rp}$ & 1.250 .000 & 1 & $\mathrm{Rp}$ & 1.562 .500 \\
\hline 19 & Pendidik & Guru & Penjaskes & - & Rp 50.000 & $\mathrm{Rp}$ & 1.250 .000 & 3 & $\mathrm{Rp}$ & 3.750 .000 \\
\hline 20 & Pendidik & Guru & Ketrampilan / TIK & - & Rp 50.000 & $\mathrm{Rp}$ & 1.250 .000 & 3 & $\mathrm{Rp}$ & 3.750 .000 \\
\hline & & & Tot & & & & & & Rp & 53.812 .500 \\
\hline
\end{tabular}

Untuk biaya pengajar dan SDM yang ada di pondok pesantren menggunakan cara sebagai berikut :

Total $=\sum T j+(B p j \times J m)$

Dimana Tj adalah biaya tunjangan yang diberikan pondok pesantren terhadap setiap jabatan yang ada di pondok pesantren. Bpj merupakan tarif per jam, dan Jm merupakan jam mengajar. 
Jurnal Riset Sistem Informasi Dan Teknik Informatika (JURASIK)

Volume 5 Nomor 2 Agustus, pp 187-193

ISSN: 2527-5771/EISSN: 2549-7839

https://tunasbangsa.ac.id/ejurnal/index.php/jurasik

Tabel 4. Data Biaya Gedung

\begin{tabular}{|c|c|lr|lr|}
\hline No & Nama & \multicolumn{2}{|c|}{ Biaya Satuan } & \multicolumn{2}{c|}{ Total Biaya } \\
\hline 1 & Gedung Mahad & $\mathrm{Rp}$ & 800.000 .000 & $\mathrm{Rp}$ & 1.600 .000 .000 \\
\hline 2 & Kantin & $\mathrm{Rp}$ & 50.000 .000 & $\mathrm{Rp}$ & 100.000 .000 \\
\hline 3 & Ruangan Belajar & $\mathrm{Rp}$ & 20.000 .000 & $\mathrm{Rp}$ & 180.000 .000 \\
\hline 4 & Masjid & $\mathrm{Rp}$ & 1.000 .000 .000 & $\mathrm{Rp}$ & 1.000 .000 .000 \\
\hline 5 & Kamar mandi & $\mathrm{Rp}$ & 30.000 .000 & $\mathrm{Rp}$ & 480.000 .000 \\
\hline 6 & Ruang Kesehatan & $\mathrm{Rp}$ & 50.000 .000 & $\mathrm{Rp}$ & 50.000 .000 \\
\hline 7 & Rumah Pengasuh & $\mathrm{Rp}$ & 150.000 .000 & $\mathrm{Rp}$ & 600.000 .000 \\
\hline 8 & Rumah Ustad & $\mathrm{Rp}$ & 80.000 .000 & $\mathrm{Rp}$ & 800.000 .000 \\
\hline 9 & Rumah kyai & $\mathrm{Rp}$ & 200.000 .000 & $\mathrm{Rp}$ & 400.000 .000 \\
\hline 10 & koperasi & $\mathrm{Rp}$ & 80.000 .000 & $\mathrm{Rp}$ & 80.000 .000 \\
\hline 11 & Aula & $\mathrm{Rp}$ & 60.000 .000 & $\mathrm{Rp}$ & 60.000 .000 \\
\hline 12 & perpustakaan & $\mathrm{Rp}$ & 50.000 .000 & $\mathrm{Rp}$ & 50.000 .000 \\
\hline \multicolumn{5}{|c|}{ Total Biaya } & $\mathrm{Rp}$ \\
\hline
\end{tabular}

Untuk menghitung biaya gedung pada pondok pesantren, menggunakan rumus :

Total Biaya $=\sum \frac{B G \times J G}{B W G}$

Dimana BG merupakan biaya untuk membangun gedung, JG merupakan jumlah gedung yang akan dibangun, dan BWG merupakan batas waktu penggunaan sebuah gedung.

Tabel 5. Biaya Buku perSemester

\begin{tabular}{|c|l|rr|lr|}
\hline No & Mata Pelajaran & \multicolumn{2}{|c|}{ Biaya Per Santri } & \multicolumn{2}{c|}{ Total Biaya } \\
\hline 1 & Pendidikan Agama & $\mathrm{Rp}$ & 50.000 & $\mathrm{Rp}$ & 15.000 .000 \\
\hline 2 & Pendidikan Kwn & $\mathrm{Rp}$ & 50.000 & $\mathrm{Rp}$ & 15.000 .000 \\
\hline 3 & Bahasa Indonesia & $\mathrm{Rp}$ & 50.000 & $\mathrm{Rp}$ & 15.000 .000 \\
\hline 4 & Bahasa Inggris & $\mathrm{Rp}$ & 50.000 & $\mathrm{Rp}$ & 15.000 .000 \\
\hline 5 & Matematika & $\mathrm{Rp}$ & 50.000 & $\mathrm{Rp}$ & 15.000 .000 \\
\hline 6 & Ilmu Pengetahuan Alam & $\mathrm{Rp}$ & 50.000 & $\mathrm{Rp}$ & 15.000 .000 \\
\hline 7 & Ilmu Pengetahuan Sosial & $\mathrm{Rp}$ & 50.000 & $\mathrm{Rp}$ & 15.000 .000 \\
\hline 8 & Seni Budaya & $\mathrm{Rp}$ & 50.000 & $\mathrm{Rp}$ & 15.000 .000 \\
\hline 9 & Penjaskes & $\mathrm{Rp}$ & 50.000 & $\mathrm{Rp}$ & 15.000 .000 \\
\hline 10 & Ketrampilan / TIK & $\mathrm{Rp}$ & 50.000 & $\mathrm{Rp}$ & 15.000 .000 \\
\hline 11 & Kitab Tauhid & $\mathrm{Rp}$ & 50.000 & $\mathrm{Rp}$ & 15.000 .000 \\
\hline 12 & Kitab Tafsir & $\mathrm{Rp}$ & 50.000 & $\mathrm{Rp}$ & 15.000 .000 \\
\hline 13 & Kitab Hadits & $\mathrm{Rp}$ & 50.000 & $\mathrm{Rp}$ & 15.000 .000 \\
\hline 14 & Kitab Fiqh & $\mathrm{Rp}$ & 50.000 & $\mathrm{Rp}$ & 15.000 .000 \\
\hline 15 & Kitab Ushul Fiqh & $\mathrm{Rp}$ & 50.000 & $\mathrm{Rp}$ & 15.000 .000 \\
\hline 16 & Kitab Tashawuf & $\mathrm{Rp}$ & 50.000 & $\mathrm{Rp}$ & 15.000 .000 \\
\hline 17 & Bahasa Arab (Nahwu, Sha & $\mathrm{Rp}$ & 100.000 & $\mathrm{Rp}$ & 30.000 .000 \\
\hline 18 & Kitab Mantiq & $\mathrm{Rp}$ & 50.000 & $\mathrm{Rp}$ & 15.000 .000 \\
\hline 19 & Kitab Akidah Akhlak & $\mathrm{Rp}$ & 50.000 & $\mathrm{Rp}$ & 15.000 .000 \\
\hline & & & $\mathrm{Rp}$ & 300.000 .000 \\
\hline
\end{tabular}

Dalam perhitungan biaya buku pelajaran berbeda dengan biaya sarpras dan biaya gedung. Untuk menghitung biaya pengadaan buku pelajaran digunakan rumus: 
Jurnal Riset Sistem Informasi Dan Teknik Informatika (JURASIK)

Volume 5 Nomor 2 Agustus, pp 187-193

ISSN: 2527-5771/EISSN: 2549-7839

https://tunasbangsa.ac.id/ejurnal/index.php/jurasik

Total $=\sum($ Harga satuan buku $\times$ jumlah siswa $)$

Kemudian selanjutnya jumlahkan dengan semua total harga buku satuan untuk mengetahui total biaya pengadaan buku santri selama satu semester.

Tabel 6. Biaya Operasional Pembangunan pada Pondok Pesantren

\begin{tabular}{|c|c|c|c|c|c|c|c|c|}
\hline \multirow{2}{*}{$\begin{array}{c}\text { No } \\
1 \\
\end{array}$} & \multirow{2}{*}{$\begin{array}{c}\text { Nama Kegiatan } \\
\text { Biaya Pengadaan Kitab }\end{array}$} & \multirow[b]{2}{*}{ Transport } & \multicolumn{2}{|c|}{ Tarif } & \multicolumn{2}{|c|}{ Biaya Total } & \multicolumn{2}{|c|}{ Total Sampai Lulus } \\
\hline & & & $\mathrm{Rp}$ & 15.000 & $\mathrm{Rp}$ & 15.000 & $\mathrm{Rp}$ & 90.000 \\
\hline & & Uang Makan & $\mathrm{Rp}$ & 10.000 & $\mathrm{Rp}$ & 10.000 & $\mathrm{Rp}$ & 60.000 \\
\hline \multirow[t]{7}{*}{2} & Ujian & Biaya Pembuatan Soal & $\mathrm{Rp}$ & 50.000 & $\mathrm{Rp}$ & 50.000 & $\mathrm{Rp}$ & 300.000 \\
\hline & & Biaya Pencetakan Soal & $\mathrm{Rp}$ & 5.000 & $\mathrm{Rp}$ & 5.000 & $\mathrm{Rp}$ & 30.000 \\
\hline & & Biaya Pencetakan Absen Santri & $\mathrm{Rp}$ & 2.000 & $\mathrm{Rp}$ & 2.000 & $\mathrm{Rp}$ & 12.000 \\
\hline & & Biaya Pencetakan Absen Pengawas & $\mathrm{Rp}$ & 2.000 & $\mathrm{Rp}$ & 2.000 & $\mathrm{Rp}$ & 12.000 \\
\hline & & Biaya Kosumsi Pengawas & $\mathrm{Rp}$ & 10.000 & $\mathrm{Rp}$ & 10.000 & $\mathrm{Rp}$ & 60.000 \\
\hline & & Biaya Pencetakan No Ujian + Ruangan & $\mathrm{Rp}$ & 500 & $\mathrm{Rp}$ & 500 & $\mathrm{Rp}$ & 3.000 \\
\hline & & Biaya Pembuatan Kartu Peserta Ujian & $\mathrm{Rp}$ & 2.500 & $\mathrm{Rp}$ & 2.500 & $\mathrm{Rp}$ & 15.000 \\
\hline 3 & Raport & Biaya Pencetakan Raport & $\mathrm{Rp}$ & 60.000 & $\mathrm{Rp}$ & 60.000 & $\mathrm{Rp}$ & 60.000 \\
\hline \multicolumn{7}{|c|}{ Total } & Rp & 642.000 \\
\hline
\end{tabular}

Untuk menghitung biaya operasional pembangunan pada pondok pesantren dengan menggunakan rumus:

Biaya Total $=\sum(T b k \times J u)$

Dimana Tbk merupakan tariff biaya kegiatan dan Ju merupakan jumlah unit. Yang dimaksud dengan jumlah unit adalah jika kegiatan tersebut berhubungan dengan santri.

Tabel 7. Hasil Otomasi

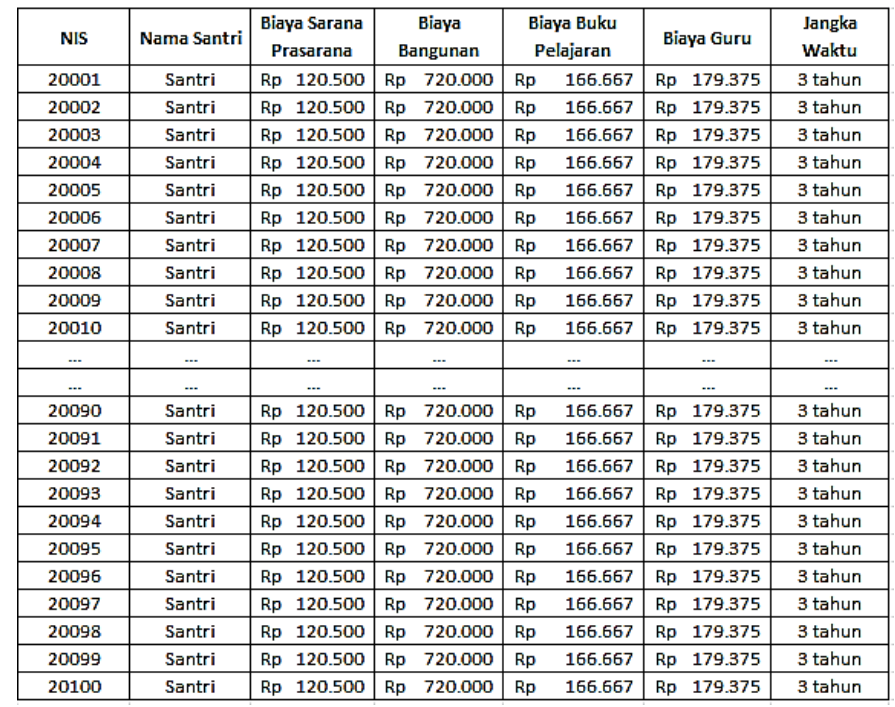

Hasil otomasi di atas adalah otomasi produksi pesanan pada tabel pesanan yang menginputkan kode produk pada Tabel hasil proses otomasi, sehingga akan muncul 
Jurnal Riset Sistem Informasi Dan Teknik Informatika (JURASIK)

Volume 5 Nomor 2 Agustus, pp 187-193

ISSN: 2527-5771/EISSN: 2549-7839

https://tunasbangsa.ac.id/ejurnal/index.php/jurasik

detail secara otomatis. Selanjutnya untuk perhitungan biaya setiap produk (santri) per bulan yaitu dengan menggunakan rumus :

Total Biaya $=\sum \frac{\text { Total Biaya per unit }}{\text { Batas pakai unit } \times \text { jumlah santri }}$

Sehingga akan diperoleh hasil seperti pada Tabel 8.

Tabel 8. Total biaya setiap santri per bulan

\begin{tabular}{|c|l|lr|}
\hline No & Nama & \multicolumn{2}{|c|}{ Biaya Per Santri } \\
\hline 1 & Biaya Sarpras & $\mathrm{Rp}$ & 120.500 \\
\hline 2 & Biaya Bangunan & $\mathrm{Rp}$ & 720.000 \\
\hline 3 & Biaya Buku Pelajaran & $\mathrm{Rp}$ & 166.667 \\
\hline 4 & Biaya Guru & $\mathrm{Rp}$ & 179.375 \\
\hline \multicolumn{2}{r|}{ Total Biaya } & $\mathbf{R p}$ & $\mathbf{1 . 1 8 6 . 5 4 2}$ \\
\hline
\end{tabular}

Selanjutnya yaitu melakukan percobaan dengan mengubah jumlah lulusan dan jumlah santri agar dapat mengetahui pergerakan nilai biaya per santri per bulannya.

\section{SIMPULAN}

Penelitian ini membahas mengenai otomasi perencanaan produksi pada pondok pesantren. Otomasi yang dimaksudkan adalah dengan melakukan perhitungan biaya perencanaan produksi menggunakan program Excel dengan parameternya adalah jumlah santri. Teknik yang digunakan dalam perencanaan produksi ini dengan menggunakan Teknik ABC (Activity-Based Costing) yang dapat mengakumulasi biaya serta aktivitas dari produk. Dengan adanya perencanaan produksi perusahaan dapat mempertimbangkan perencanaan yang dilakukan sebelum melakukan kegiatan produksi.

\section{DAFTAR PUSTAKA}

[1] Rahmadani, Nurfatimah \& Andi Wawo. (2016). Penentuan Harga Pokok Produksi Pembangunan Pembangunan Rumah dengan Menggunakan Metode Activity Based Costing (STUDI PADA PERUM PERUMNAS REGIONAL VII MAKASSAR). Jurnal Ilmiah Akuntansi Peradaban, 2(1). 108-128.

[2] F, M. A. (2017). Integrasi Sistem Informasi Perencanaan Produksi Pada Enterprise Resource Planning Pondok Pesantren Tipe D Menggunakan Service Oriented Architecture. Malang: Etheses of Maulana Malik Ibrahim State Islamic University.

[3] S, R. M., \& J, W. (2012). Integrated Business Processes with ERP Systems. Wiley Publishing .

[4] Buffa, E. dan Sarin, R. 1996. Manajemen Operasi dan Produksi Modern, Jilid 1 Edisi Kedelapan. Binarupa Aksara, Jakarta.

[5] Arief, I. R. (2015). Perancangan Purwarupa Sistem Pengendalian Kualitas Pengukuran Dimensi Produk Terotomasi. 